\title{
Developing official control in slaughterhouses through internal audits
}

\author{
Luukkanen, Jenni
}

2018

Luukkanen , J , Nevas , M , Fredriksson-Ahomaa , M \& Lundén , J 2018 , ' Developing

official control in slaughterhouses through internal audits ', Food Control, vol. 90 , pp.

344-351 . https://doi.org/10.1016/j.foodcont.2018.03.014

http://hdl.handle.net/10138/308935

https://doi.org/10.1016/j.foodcont.2018.03.014

cc_by_nc_nd

acceptedVersion

Downloaded from Helda, University of Helsinki institutional repository.

This is an electronic reprint of the original article.

This reprint may differ from the original in pagination and typographic detail.

Please cite the original version. 
1 Developing official control in slaughterhouses through internal audits

2 Jenni Luukkanen ${ }^{a *}$, Mari Nevas ${ }^{a}$, Maria Fredriksson-Ahomaa ${ }^{a}$, Janne Lundén ${ }^{a}$

3 Department of Food Hygiene and Environmental Health, Faculty of Veterinary Medicine,

4 P.O. Box 66, 00014 University of Helsinki, Finland

5

6

7

8

9

$23{ }^{*}$ Corresponding author

24 Department of Food Hygiene and Environmental Health

25 Faculty of Veterinary Medicine

26 P.O. Box 66, 00014 University of Helsinki, Finland

27 E-mail: jenni.luukkanen@helsinki.fi 
In the European Union, competent authorities are obligated to arrange audits to ensure that the official control (comprising meat and food safety inspections) in slaughterhouses is performed according to legislation. Previous information on the functionality of these audits and on nonconformities observed in the official control of slaughterhouses is limited. In this study, nonconformities of the official control of slaughterhouses and their correction were analysed from the internal audit reports of the Finnish Food Safety Authority Evira. To further assess the benefits and needs for improvement of the audits, we conducted interviews with the chief official veterinarians (OVs) responsible for the controls in slaughterhouses and the auditors of Evira. According to our results, non-conformities, especially in the inspection of intestines of bovines and swine, were common. Regarding food safety inspections, OVs should develop their documentation, perform the follow-up of the correction of non-compliances more systematically, and improve the enforcement, especially in smaller red meat slaughterhouses. Based on our results, internal audits appeared to be beneficial, as non-conformities in the official control were noticed, most non-conformities were corrected or corrective measures had been taken, and the audits were assessed as necessary by both the auditors and auditees. Our results can be utilized in improving the official control and audit procedures in slaughterhouses. In the future, the uniformity of meat inspection could be improved by auditing also differences in the rejections and their reasons between official auxiliaries in postmortem inspection.

Keywords: non-conformity, meat inspection, food safety inspection, non-compliance, correction

1 Introduction

In slaughterhouses, official veterinarians (OVs) bear the primary responsibility for official control comprising meat and food safety inspections (European Union [EU], 2004a). The goal of meat

55 inspection, which may be performed with assistance from official auxiliaries (OAs), is to ensure 56 safe meat for consumers, secure the welfare of animals, and prevent transmissible animal 
diseases (Alban, Steenberg, Stephensen, Olsen, \& Petersen, 2011; European Food Safety Authority [EFSA], 2011; EU, 2004a). Meat inspection consists of the inspection of food chain information, live animals (ante-mortem inspection), and carcasses and offal (post-mortem inspection). In Finland, OAs perform post-mortem inspection under the supervision of the OVs in red meat and poultry slaughterhouses. Food safety inspections are performed to verify slaughterhouses' compliance with food safety legislation including proper implementation of slaughterhouses' obligatory self-checking systems (SCSs). These SCSs are based on basic hygiene and hazard analysis and critical control point (HACCP) principles (EU, 2004c). A wellimplemented SCS ensures, for instance, adequate process hygiene (Blagojevic \& Antic, 2014; Food and Agriculture Organization, 2004), thus contributing to meat safety (Blagojevic \& Antic, 2014; Nørrung \& Buncic, 2008). In practice, food safety inspections entail a comprehensive examination of various areas, such as maintenance and hygiene of premises and equipment, temperature control, and employee practices. In Finland, OVs perform food safety inspections, but OAs could participate by collecting information regarding good hygienic practices and HACCPbased procedures (EU, 2004a).

To guarantee that official controls in food establishments, including slaughterhouses, meet their objectives, the competent authorities of each EU member state are obligated to arrange either internal or external audits by which the official controls are evaluated (EU, 2004b). In slaughterhouses of Finland, the Finnish Food Safety Authority Evira has performed internal audits; its auditors have also been involved in guiding and organizing official control in slaughterhouses. Audits have been considered to be a good instrument to improve the functionality of organizations (Bawole \& Ibrahim, 2016; Junttila, 2014; Leeuw, 2011), but to our knowledge, their efficacy in relation to slaughterhouse control has not been investigated in Finland or in other countries. In some of the European countries, including Finland, the number of audits of official control has decreased because of scarce economic resources (European Commission [EC], 2013). This further highlights the need to assess whether the audits have been performed in the most efficient way and whether they truly contribute to better control. The optimal frequency of audits should also 
be determined. To receive a comprehensive view of the benefits and needs for improvement of the internal audits, both OVs' and auditors' views should be investigated.

Non-conformities in relation to post-mortem inspection have been reported at a general level to occur widely in European countries (Alban et al., 2011; EFTA [European Free Trade Association] Surveillance Authority, 2012; EC, 2013), and authorities have had problems in identifying and addressing non-compliance of slaughterhouses (Alban et al., 2011). In Finland, a previous study indicated that more efficient control measures should be used by the OVs in some slaughterhouses (Luukkanen \& Lundén, 2016). In order to develop the official control in slaughterhouses, more thorough investigation of the frequencies and types of non-conformities should be performed.

96

Our study aimed to identify the types of non-conformities occurring in official control of slaughterhouses and to examine the benefits of internal audits on official control. The optimal frequency and potential need for improvement of internal audits were also investigated. The results of this research can be used to enhance the official control and auditing procedures in slaughterhouses.

\section{Materials and methods}

\subsection{Audit reports}

In total, 38 reports of internal audits of meat inspection in 19 slaughterhouses (performed by the meat inspection unit of Evira) and 22 reports of internal audits of food safety inspections in 17 slaughterhouses (performed by the food hygiene unit of Evira) were analysed (Table 1). Audit reports of meat inspection were from the period 2009-2013 and audit reports of food safety

111 the meat inspection unit. Meat inspection was audited twice, but food safety inspections only once 112 in the majority of the slaughterhouses (Table 1). Small-scale slaughterhouses processing under 20 
livestock units (one livestock unit = one bovine or five pigs) per week, under 1000 livestock units per year, or under 150000 birds per year (Ministry of Agriculture and Forestry, 2011) were excluded from the study. The audits followed clear instructions in which, for instance, the aims and the course of audits were described in detail (Evira, 2010, 2011). Post-mortem inspection performed by OAs was audited in red meat slaughterhouses. In poultry slaughterhouses, OVs' supervisory duties in post-mortem inspection, including the inspection of a representative sample of birds and a detailed inspection of a random sample of birds declared unfit for human consumption by the OAs (EU, 2004a), were audited. Non-conformities (in meat and food safety inspections) and targets for development (only in food safety inspections) and their numbers were analysed. Auditing units had defined observations not complying with the legislation or Evira's instructions as non-conformities, whereas observations that were not non-conformities, but the correction of which would contribute to the efficacy of food safety inspections were defined as targets for development. The correction of non-conformities was also analysed based on following audits or on OVs' reports of corrective measures. One audit report and two of the OVs' reports of corrective measures (one from each auditing unit) were not available because they had not been filed in a uniform way.

\subsection{Statistical analysis of the audit reports}

Statistical analysis was performed with SPSS 21.0 (SPSS IBM, Armonk, NY, USA). Nonconformities and targets for development were analysed between red meat and poultry slaughterhouses and between slaughterhouses of different size. Slaughterhouses were divided into two groups of approximately the same size based on information on the number of slaughtered animals received from Evira. Larger slaughterhouses $(n=10)$ processed over 1000 red meat animals or over 200000 birds per week and smaller slaughterhouses $(n=9)$ less than these figures. Statistical differences in the occurrence of non-conformities and targets for development in each area of official control between slaughterhouses were tested with Fisher's exact test. Differences between slaughterhouses in the number of areas of official control in which non- 
conformities and targets for development were observed were analysed with Mann-Whitney U-test. A confidence level of $95 \%$ was used in evaluating the results.

\subsection{Interviews}

To examine internal audits of meat and food safety inspections in the slaughterhouses from OVs' and auditors' point of view, a semi-structured interview was conducted. In this interview method, a set of questions was used and asked in a systematic order, but the researcher was also allowed probing questions (Fylan, 2005). The interview included both structured and open-ended questions regarding the necessity, benefits, preferred frequency, and potential need for improvement of the audits. Questions on how necessary and beneficial the internal audits were had a scale ranging from zero to ten (only minimum and maximum values were defined verbally). At the end of the interview, the interviewees were allowed to clarify their answers. Interviews were conducted by a single researcher and the answers were simultaneously written down. Before the interviews, participants were informed of the purpose of the study and assured of the anonymity of their responses. In total, chief OVs from 13 slaughterhouses and 8 central officials involved in the internal audits of slaughterhouses participated in the interview in May-June 2015. Henceforth, for clarity the interviewed central officials are referred to as auditors, although one of interviewees had not been auditing, but was closely overseeing the auditing procedures and planning the audits. At the time of the interviews, Finland had 19 slaughterhouses, but two of these slaughterhouses did not have a regular OV and in four slaughterhouses the chief OVs declined to participate in the interview because of time constraints. Ultimately, chief OVs from $2 / 5$ poultry slaughterhouses and $11 / 14$ red meat slaughterhouses participated. Chief OVs' interviews were conducted by Microsoft Lync 2013 approximately 47 (range 15-80) minutes and auditors' interviews approximately 77 (range 60-90) minutes. 


\subsection{Analysis of interviews} The interviews were analysed using inductive content analysis to identify thematic categories (Elo \& Kyngäs, 2008; Franzosi, 2009; Vaismoradi, Turunen, \& Bondas, 2013) in relation to the following questions: a) What are the benefits gained from the audits? and b) How should the audits be improved in the future? An initial coding of the responses was made, related codes were grouped into subcategories, and their frequencies were calculated. The final categories were formed by grouping the subcategories. Initial coding and construction of the themes were manually performed by one researcher. Themes were discussed with fellow authors and a concensus was reached. Answers to questions with a scale from zero to ten were analysed using SPSS 21.0 (SPSS IBM, Armonk, NY, USA). Differences in the means of the answers between different respondent groups were analysed with Mann-Whitney U-test. The Wilcoxon signed-rank test, which is used to test the distribution of dependent samples, was applied for the OVs' responses on how beneficial audits were for meat and food safety inspections. A confidence level of $95 \%$ was used.

\section{Results}

3.1 Non-conformities in post-mortem inspection and meat inspection documentation

Non-conformities in the technical post-mortem inspection of bovine were observed in at least one audit in nearly all (10/11) of the slaughterhouses (Table 2). The most common non-conformities were related to palpation and possible incision of the gastric and mesenteric lymph nodes (observed in ten slaughterhouses) and visual inspection of the udder and its lymph nodes (observed in six slaughterhouses). In the technical post-mortem inspection of swine, nonconformities were also observed in at least one audit in nearly all $(5 / 7)$ of the slaughterhouses (Table 2). The most common non-conformities were related to visual inspection of the gastrointestinal tract and gastric and mesenteric lymph nodes and their palpation (observed in five slaughterhouses). In the majority of the bovine or swine slaughterhouses where non-conformities in palpation of the gastric and mesenteric lymph nodes or inspection of the udder were observed, the correction of the non-conformity demanded structural changes to the slaughter line or recruiting 
an extra OA. No significant difference was present in the occurrence or number of non-conformities

197 in the technical post-mortem inspection between larger and smaller red meat slaughterhouses $(p<$ 0.05 , Fisher's exact test and Mann-Whitney U-test).

The majority of the non-conformities in the technical post-mortem inspection of bovine and swine (50/60) were corrected or their correction had been initiated (Figure 1). Of the non-conformities, $37 \%(22 / 60)$ were corrected based on the subsequent audits, and in $47 \%(28 / 60)$ OVs had taken corrective measures according to their reports (Figure 1). In one slaughterhouse, two nonconformities had not been corrected according to the OV's report because proper inspection of bovine gut lymph nodes and udders would have demanded structural changes to the slaughter line. According to their reports, OVs had started corrective measures in two of three of the nonconformities that were not corrected in subsequent audits. The correction of the rest of the nonconformities was unclear because OVs had not reported the measures taken (six non-conformities) (Figure 1).

In poultry slaughterhouses, auditors observed non-conformities in the daily inspections performed by the OV in one of the four slaughterhouses (Table 2). In this particular slaughterhouse, the OV did not perform the daily inspection of the viscera and body cavities of a representative sample in all cases due to a problematic construction of the slaughter line, and also the detailed inspection of a random sample of condemned carcasses was insufficient (Table 2). Both of these nonconformities had been corrected based on audits.

218 Non-conformities in the documentation of meat inspection were uncommon (Table 2) and 219 concerned insufficiently identified animals and the meat inspection decision. These nonconformities were corrected after the audit according to the OVs' reports.

2223.2 Non-conformities and targets for development in food safety inspections 
223 In the audits of food safety inspections, non-conformities were observed in $7 / 13$ red meat 224 slaughterhouses and in none of the poultry slaughterhouses. The most common non-conformities concerned documentation of food safety inspections and control measures (Table 3). Nonconformities in documentation (observed in three smaller and two larger slaughterhouses) included insufficient documentation of inspected areas, observations, or given time limits for corrections. In two smaller slaughterhouses, the OVs could not present any documentation of the food safety inspections. Non-conformities in control measures (observed in two smaller and two larger slaughterhouses) included lack of systematically ensuring the approval of changes in operations and premises, and too seldom or insufficient checks of the SCS, including HACCP. During the audits OVs performed a routine food safety inspection observed by the auditors, and in two smaller red meat slaughterhouses OVs did not detect non-compliance such as deficiencies in hygiene or handling of by-products. The enforcement performed by the OVs was also observed to have nonconformities in one larger slaughterhouse. Auditors stated that the OV had not started the required enforcement measures in relation to correction of unhygienic structures. The control plan was missing or insufficient in two slaughterhouses (Table 3).

Targets for development were observed in the food safety inspections in most (15/17) of the slaughterhouses and in the same areas as non-conformities (Table 3). The auditors found targets for development especially in documentation (in 12/17 slaughterhouses) but also in the follow-up of the correction of non-compliances (in 9/16 slaughterhouses), as the auditors were left with the impression that the OVs did not conduct follow-up inspections systematically after the time limit for the correction had passed (Table 3). Targets for development in enforcement included, for example, that the OVs should have been more prone to use enforcement measures (in two slaughterhouses), as neither slaughterhouse had complied with the time limits set for corrections (Table 3).

The number of smaller red meat slaughterhouses in which non-conformities or targets for development (together referred to as deficiencies) were observed in at least one audit in the 
271

enforcement (5/6) was significantly greater than the number of larger red meat slaughterhouses with these deficiences $(1 / 7)(p<0.05$, Fisher's exact test). Food safety inspections of smaller red meat slaughterhouses had also on average more areas with deficiences per slaughterhouse than larger red meat slaughterhouses, although the difference was not significant $(p=0.051$, MannWhitney U-test). No significant difference in the occurrence of deficiencies or in the number of areas with deficiencies per slaughterhouse between red meat and poultry slaughterhouses was observed ( $p>0.05$, Fisher's exact test and Mann-Whitney U-test).

Of the non-conformities in the food safety inspections, $19 \%(3 / 16)$ were observed to be corrected on the subsequent audits, and in $56 \%(9 / 16)$ OVs had taken corrective measures based on their reports. Non-conformities (13\%) that persisted to the second audit were being corrected after the audit according to OVs' reports. These non-conformities included insufficient checks of the SCS and inadequate enforcement. The OV's report was missing in one slaughterhouse concerning two non-conformities.

\subsection{Interviews}

\subsubsection{Necessity and benefits of the audits}

In the interviews, both the OVs and auditors assessed internal auditing of meat and food safety inspections on average as necessary, and respondent groups' answers did not differ significantly ( $p>0.05$, Mann-Whitney U-test) (Figure 2). OVs considered the audits to be significantly more beneficial for food safety inspection than for meat inspection $(p<0.05$, Wilcoxon signed-rank test) (Figure 2).

Benefits of the audits that were brought up by the interviewees were grouped into two categories: a) improvements to the quality of official control and b) improvements to guidance, support, and training (Table 4). OVs (11/13) most frequently mentioned that the audits were useful in enhancing the correction of slaughterhouses' non-compliances; they deemed it beneficial that auditors also 
were demanding corrections to non-conformities requiring slaughterhouses' actions. Audits were furthermore assessed as beneficial because of improvements or corrections to the official control (Table 4). Auditors (7/8) saw audits as especially important in perceiving the present state of official control in slaughterhouses (Table 4), which according to them was sometimes difficult based only on information available in the central authority's office. In relation to benefits to guidance, support, and training, some of the OVs (6/13) and all of the auditors (8/8) mentioned audits to be advantageous because of the possibility of discussion between OVs and officials from the central authority (Table 4). Support received during the audits and assessment of the need for instructions and training were also mentioned as benefits by a substantial number of interviewees (Table 4).

\subsubsection{Improving the audits}

The need for improvement of the audits mentioned by the interviewees was grouped into four categories: a) content of the audits, b) expertise of the auditor, c) audit process and practices, and d) follow-up of the audits (Table 5). The most commonly mentioned need for improvement in the content of the audits was that the audits, mainly the meat inspection audits (mentioned by $6 / 8$ respondents), should be more thorough and the uniformity of the meat inspection should be audited (mentioned by $5 / 13$ OVs). When asked whether the validity of the rejections should be audited, 11 OVs and two of three of the meat inspection auditors supported the idea. Some of the OVs $(n=6)$ and auditors $(n=2)$ considered that the auditors' should have more experience of meat inspection and as OVs in order to be able to audit more thoroughly (Table 5). In relation to needs for improvement in the audit process and practices, two OVs stated that they needed more support from their superiors when enforcement measures were deemed necessary based on audits (Table 5). Most of the auditors $(n=5)$ noted that the follow-up of the correction of nonconformities required improvement (Table 5). They mentioned that the reports should be, without exception, consistently filed, and the reports received from OVs should be more unambiguous.

\subsubsection{Frequency of audits}


Of the OVs, $62 \%(8 / 13)$ considered that both meat inspection and food safety inspections should be audited at least once every three years in each slaughterhouse, $23 \%(3 / 13)$ suggested every other year, and $15 \%(2 / 13)$ every year. According to the majority (7/8) of auditors, all slaughterhouses should be audited every other or third year.

4 Discussion

Our results show that non-conformities in inspection of the gastrointestinal tract, especially in palpation and possible incision of the gastric and mesenteric lymph nodes, were common in postmortem inspection of bovines and swine in Finland. These non-conformities had remained because their correction would have required expensive repairs to the slaughter line or recruiting of an extra OA. Similar nonconformities regarding inspection of the gastrointestinal tract and related lymph nodes have been observed commonly in other EU countries as well (Alban et al., 2011; EFTA Surveillance Authority, 2012). These results support criticism of authorities' capacity to address non-conformities and enable meat inspection to be performed according to the legislation. However, a recent study conducted in the United Kingdom concluded that especially palpation and possible incisions of the gastrointestinal tract and related lymph nodes of cattle, small ruminants, and swine have limited importance for public health (Blagojevic, Dadios, Reinmann, Guitian, \& Stärk, 2015), and manual examination has been assessed to cause cross-contamination (EFSA, 2011; Nesbakken, Eckner, Høidal, \& Røtterud, 2003; Pointon, Hamilton, Kolega, \& Hathaway, 2000). OVs may have evaluated the contribution of the inspection of the gastrointestinal tract to be of lesser importance for meat safety, with this, in part, resulting in a lack of enforcement of the problems hindering proper inspection. Especially in situations where a shortage of inspection personnel existed, prioritization of control tasks has probably been necessary. However, when performing meat inspection according to legislation demands changes to the slaughterhouse structures or requires more OAs, OVs should receive support from their superiors to ensure that sufficiently effective control measures or actions are taken to reach compliance. 
Relative to meat inspection, food safety inspections had fewer non-conformities, and in poultry slaughterhouses in this study none were observed. However, when the targets for development are taken into consideration, the results show that the OVs in Finnish slaughterhouses have room for improvement, especially in the documentation of food safety inspections and in the follow-up of correction of slaughterhouses' non-compliance. If follow-up inspections are not systematically performed and if documentation of the inspections is scanty or missing, there is a risk that the control becomes inefficient and inconsistent. Deficiencies were also observed in inspections of the SCS and especially in smaller slaughterhouses regarding the enforcement. These results are worrisome since smaller slaughterhouses, in particular, have been reported to have difficulties in implementing their SCSs, and critical non-compliance regarding hygiene, such as problems in dehiding, sterilization of knives, and cleaning, has occurred (EFTA Surveillance Authority, 2012; Food and Veterinary Office [FVO], 2002, 2013; Luukkanen \& Lundén, 2016). In cases where slaughterhouses' SCSs fail, it is very important that the OVs address non-compliance effectively and take further actions if the necessary corrections are not performed. The audits of slaughterhouses in many European countries have shown that the problems in the follow-up of correction of non-compliance (FVO, 2013) and authorities' difficulties in effectively addressing noncompliance (Alban et al., 2011) are universal challenges warranting attention. Finland has recently implemented a national system for publishing food safety inspection results (Evira, 2013) that is anticipated to improve the uniformity and efficacy of food safety inspections in Finnish slaughterhouses.

Based on our results, the internal audits of slaughterhouse control appeared to be necessary and beneficial for the quality of meat and food safety inspections. They were perceived to improve the correction of slaughterhouses' non-compliance and proven to induce correction of non-conformities in official control, with the majority of non-conformities in post-mortem inspection and its documentation and in food safety inspections either corrected or their correction had been initiated. All of the OVs and auditors noted that internal audits should be performed at least every three years, but a considerable number of OVs stated that they should be performed even more 
frequently. The frequency of internal audits has declined in many countries due to economic difficulties (EC, 2013), but our results attest to the importance of these audits and suggest that their frequency should be maintained or even increased.

However, some improvements to the audits appear to be necessary. Interestingly, nearly all of the OVs were of the opinion that meat inspection audits, where only technical inspection is audited, had not been very beneficial, and therefore, the central authority should perform audits of also the rejections and the underlying reasons. In a previous study, the frequency with which OVs in Finnish red meat slaughterhouses observed post-mortem inspection performed by OAs varied considerably, and one-third of the OAs considered that the performance of the OAs in post-mortem inspection was not sufficiently evaluated (Luukkanen, Fredriksson-Ahomaa, Nevas \& Lundén, 2017). Insufficient supervision of meat inspection by OVs has been reported also in other EU countries (EFTA Surveillance Authority, 2012; FVO, 2002, 2013), and differences between OAs in rating lesions have been identified (Schleicher et al., 2013). These observations support the idea that the quality and uniformity of meat inspection should be evaluated, not only by the OV present at the slaughterhouse, but also by outside auditors from time to time. Should more thorough evaluation of meat inspection be performed in the future, the auditors must be experienced (Dittenhofer, 2001; International Organization of Supreme Audit Institutions, 2003; Läikkö-Roto \& Nevas, 2014) and peer-auditing could be considered. Our findings also suggest that utilization of audit results and follow-up of the correction of non-conformities should be improved; non-uniform filing of reports, for instance, resulted in the correction of some of the non-conformities in meat and food safety inspections remaining unclear. In addition, our results prompt more discussion between OVs and auditors, as these parties raised partly various needs for improvement of the audits. Auditors should be well aware of the auditees' perceptions in order to develop auditing procedures.

The auditing procedures of the official control in slaughterhouses can vary in EU countries, and Finland has decided to perform internal audits, where the auditors are involved in guiding and organizing official control in slaughterhouses. However, according to the European Commission 
391 (EC, 2006), the auditors should be independent of the activity being audited. How the auditors'

392

393 involvement in the audited controls could affect audit results is difficult to determine, but possible unwillingness of the auditors to spot deficiencies would be a potential drawback. However, this did not appear to be the case, as many non-conformities and targets for development were observed during audits. Also none of the respondents suggested that auditors' involvement in guiding and organizing official control ought to be changed in the future. On the contrary, auditors' involvement in the audited controls may have had some positive effects since a considerable number of the OVs assessed the audits as having benefitted their guidance and support. Auditors also noted that the audits had increased their knowledge of the present state of official control and its problems, increased their expertise, and enabled them to assess the training needs of OVs. These are important positive effects because many chief OVs in a previous study in Finland did not consider central officials' knowledge of the practical problems involved in OVs' work to be sufficient (Luukkanen et al., 2017).

In conclusion, the internal audits performed by the central authority in slaughterhouses proved to be beneficial for the quality of official control in Finnish slaughterhouses. Most of the nonconformities observed during the audits in the meat and food safety inspections were corrected or their correction had been initiated as a result of the audits, and both the OVs and auditors assessed the audits as necessary. When actions of a more difficult nature, such as expensive correction of slaughter line structures or an increase in the number of OAs, are required, the OVs should receive adequate support from their superiors. Other areas that should receive attention are the enforcement of corrections, documentation of food safety inspections, and a systematic approach to follow-up inspections performed by the OVs. More thorough auditing of meat inspection to enhance the uniformity of controls was also proposed by the OVs.

\section{Declarations of interest}

None. 


\section{Acknowledgements}

The authors thank the chief OVs and auditors for their co-operation. This work was supported by the Ministry of Agriculture and Forestry, Finland (grant no. 1825/312/2012).

\section{References}

Alban, L., Steenberg, B., Stephensen, F. T., Olsen, A.-M., \& Petersen, J. V. (2011). Overview on current practices of meat inspection in the EU. http://www.efsa.europa.eu/en/supporting/doc/190e.pdf Accessed 7 March 2018.

Bawole, J. N., \& Ibrahim, M. (2016). Contesting claims on measuring performance in the public sector using performance audits: Evidence from the literature. Public Organization Review, $16,285-299$.

Blagojevic, B., \& Antic, D. (2014). Assessment of potential contribution of official meat inspection and abattoir process hygiene to biological safety assurance of final beef and pork carcasses. Food Control, 36, 174-182.

Blagojevic, B., Dadios, N., Reinmann, K., Guitian, J., \& Stärk, K. D. C. (2015). Green offal inspection of cattle, small ruminants and pigs in the United Kingdom: Impact assessment of changes in the inspection protocol on likelihood of detection of selected hazards. Research in Veterinary Science, 100, 31-38.

Dittenhofer, M. (2001). Performance auditing in governments. Managerial Auditing Journal, 16, 438-442.

Elo, S., \& Kyngäs, H. (2008). The qualitative content analysis process. Journal of Advanced Nursing 62, 107-115.

European Commission. (2006). Comission Decision of 29 September 2006 setting out the guidelines laying down criteria for the conduct of audits under Regulation (EC) No $882 / 2004$ of the European Parliament and of the Council on official controls to verify compliance with feed and food law, animal health and animal welfare rules. http://eurlex.europa.eu/LexUriServ/LexUriServ.do?uri=OJ:L:2006:278:0015:0023:EN:PDF Accessed 7 March 2018. 
European Commission. (2013). Report from the Commission to the European Parliament and to the Council on the overall operation of official controls in the Member States on food safety, animal health and animal welfare, and plant health. (Report $\operatorname{COM}(2013) 681$ ). http://eur-lex.europa.eu/LexUriServ/LexUriServ.do?uri=COM:2013:0681:FIN:EN:PDF Accessed 7 March 2018.

European Food Safety Authority. (2011). Scientific Opinion on the public health hazards to be covered by inspection of meat (swine). EFSA Journal, 9(10): 2351. http://onlinelibrary.wiley.com/doi/10.2903/j.efsa.2011.2351/epdf Accessed 7 March 2018.

European Free Trade Association Surveillance Authority. (2012). Final report of EFTA Surveillance Authority mission to Iceland from 7 to 16 May 2012 regarding the application of EEA legislation related to the safety of food of animal origin, in particular meat, milk and their products. http://www.eftasurv.int/media/reports/644199_Final-report-from-a-mission-toIceland-from-7-to-16-May-2012-regarding-application.pdf Accessed 7 March 2018.

European Union. (2004a). Regulation (EC) No 854/2004 of the European Parliament and of the Council of 29 April 2004 laying down specific rules for the organisation of official controls on products of animal origin intended for human consumption. from http://eurlex.europa.eu/LexUriServ/LexUriServ.do?uri=OJ:L:2004:226:0083:0127:EN:PDF Accessed 7 March 2018.

European Union. (2004b). Regulation (EC) No 882/2004 of the European Parliament and of the Council of 29 April 2004 on official controls performed to ensure the verification of compliance with feed and food law, animal health and animal welfare rules. http://eurlex.europa.eu/LexUriServ/LexUriServ.do?uri=OJ:L:2004:165:0001:0141:EN:PDF Accessed 7 March 2018.

European Union. (2004c). Regulation (EC) No 852/2004 of the European Parliament and of the Council of 29 April 2004 on the hygiene of foodstuffs. http://eurlex.europa.eu/LexUriServ/LexUriServ.do?uri=OJ:L:2004:139:0001:0054:en:PDF Accessed 7 March 2018.

Evira. (2010). Handbook of the auditor. Evira's guidelines 10014/1. 
Evira. (2011). Plan for the audits of the food chain in 2011-2015 (4729/006/2011).

Evira. (2013). Oiva brings consumers to the door of your company. https://www.evira.fi/en/aboutevira/publications/food/brochures/oiva-tuo-kuluttajan-yrityksesi-ovelle/ Accessed 7 March 2018.

Food and Agriculture Organization. (2004). Good practices for the meat industry. http://www.fao.org/documents/card/en/c/4b06bfe9-0c96-5d9d-9a15-534e143e23a8/ Accessed 7 March 2018.

Food and Veterinary Office. (2002). Overview of the results of a series of missions carried out during 2000-2001 to evaluate controls over pig meat production in Member States. (DG(SANCO)/9005/2002). http://ec.europa.eu/food/fvo/specialreports/sr_rep_90052002_en.pdf Accessed 7 March 2018.

Food and Veterinary Office. (2013). Overview report of a series of audits carried out in 2011 and 2012 in order to evaluate the official controls related to slaughter and processing of fresh meat, in particular fresh equine meat. (DG(SANCO) 2013-6950). http://ec.europa.eu/food/ fvo/specialreports/act_getPDF.cfm?PDF_ID=124 Accessed 7 March 2018.

Franzosi, R. (2009). Content analysis. In M. A. Hardy, \& A. Bryman (Eds.), Handbook of data analysis (pp. 547-566). London, UK: SAGE Publications, Ltd.

Fylan, F. (2005). Semi-structured interviewing. In J. Miles \& P. Gilbert (Eds.), A handbook of research methods for clinical and health psychology (pp. 65-78). New York, United States: Oxford University Press.

International Organization of Supreme Audit Institutions. (2003). Standards for Performance Auditing. (ISSAI 3000). http://www.issai.org/en_us/site-issai/issai-framework/4-auditingguidelines.htm Accessed 7 March 2018.

Junttila, J. (2014). Auditing Official Controls. In T. Ninios, J. Lundén, H. Korkeala, M. FredrikssonAhomaa (eds.), Meat inspection and control in the slaughterhouse (pp. 605-620). Chichester, UK: John Wiley \& Sons, Ltd.

Leeuw, F. L. (2011). On the effects, lack of effects and perverse effects of performance audit. In J. 

Lonsdale, P. Wilkins, \& T. Ling (Eds.) Performance auditing (pp.231-247). Cheltenham, UK: Edward Elgar Publishing Ltd.

Luukkanen, J., Fredriksson-Ahomaa, M., Nevas, M., \& Lundén, J. (2017). Prerequisites for highquality official control in Finnish slaughterhouses. Food Control, 79, 50-56.

Luukkanen, J., \& Lundén, J. (2016). Compliance in slaughterhouse and control measures applied by official veterinarians. Food Control, 68, 133-138.

Läikkö-Roto, T., \& Nevas, M. (2014). Auditing local official food control: Perceptions of auditors and auditees. Food Control, 37, 135-140.

Ministry of Agriculture and Forestry. (2011). Ministry of Agriculture and Forestry's regulation 1369/2011 on food hygiene of the food establishments. http://www.finlex.fi/fi/laki/alkup/2011 /20111369 Accessed 7 March 2018.

Nesbakken, T., Eckner, K., Høidal, H. K., \& Røtterud, O. J. (2003). Occurrence of Yersinia enterocolitica and Campylobacter spp. in slaughter pigs and consequences for meat inspection, slaughtering, and dressing procedures. International Journal of Food Microbiology, 80, 231-240.

Nørrung, B., \& Buncic, C. (2008). Microbial safety of meat in the European Union. Meat Science, 78, $14-24$.

Pointon, A. M., Hamilton, D., Kolega, V., \& Hathaway, S. C. (2000). Risk assessment of organoleptic postmortem inspection procedures for pigs. Veterinary Record, 146, 124-131.

Schleicher, C., Scheriau, S., Kopacka, I., Wanda, S., Hofrichter, J., \& Köfer, J. (2013). Analysis of the variation in meat inspection of pigs using variance partitioning. Preventive Veterinary Medicine, 111, 278-285.

Vaismoradi, M., Turunen, H., \& Bondas, T. (2013). Content analysis and thematic analysis: Implications for conducting a qualitative descriptive study. Nursing and Health Sciences, $15,398-405$. 


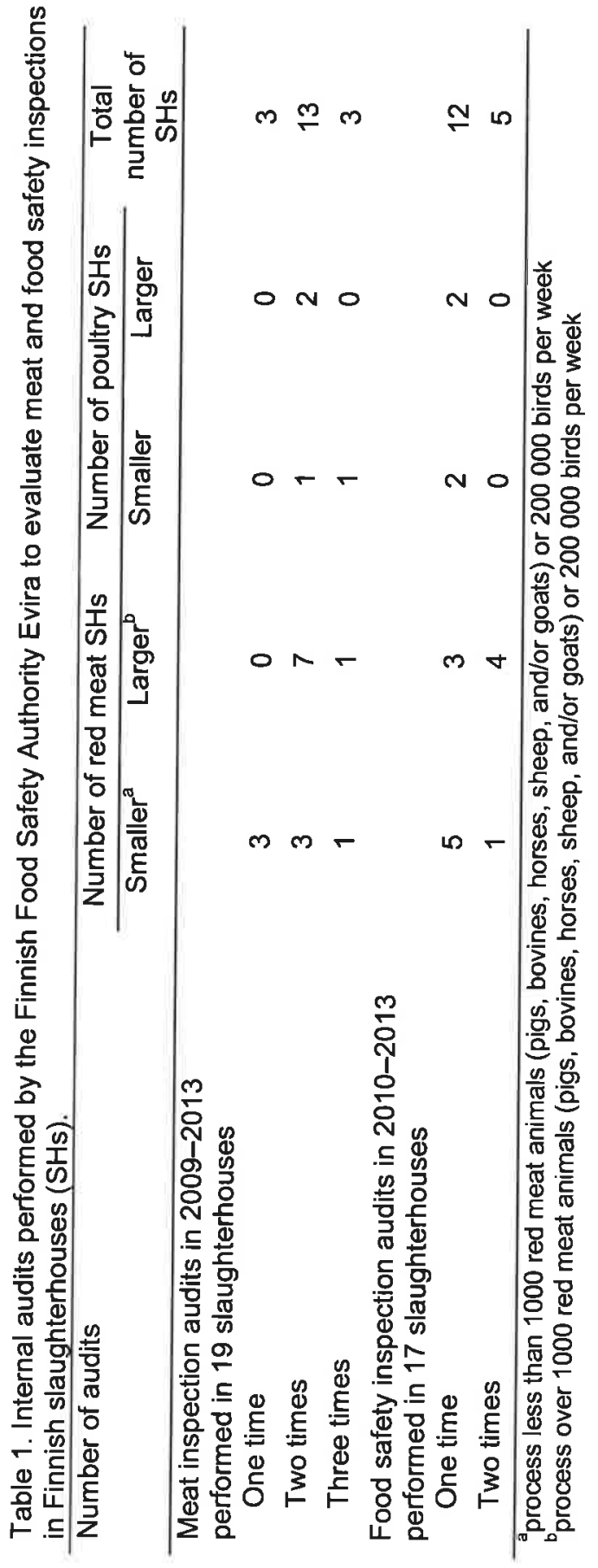




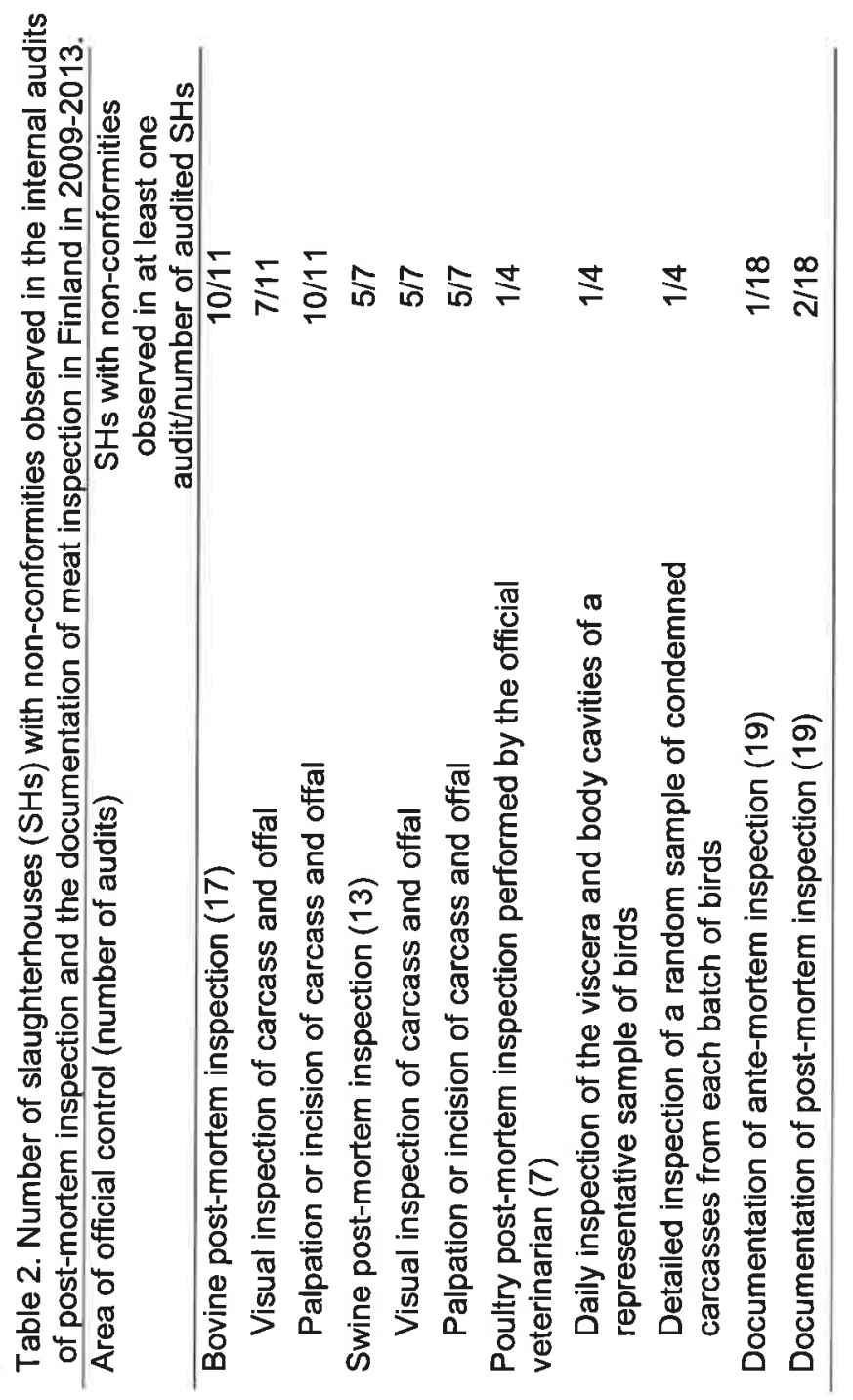




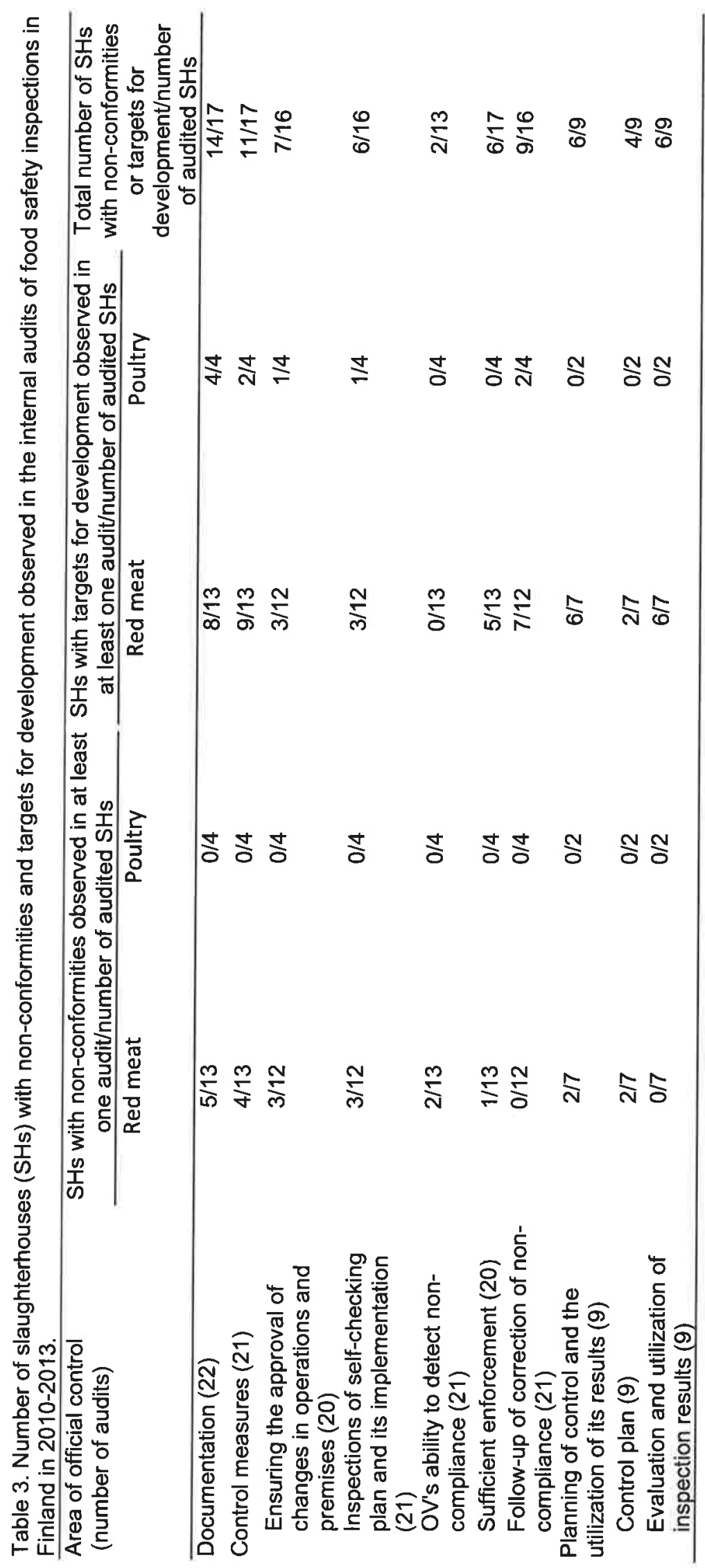




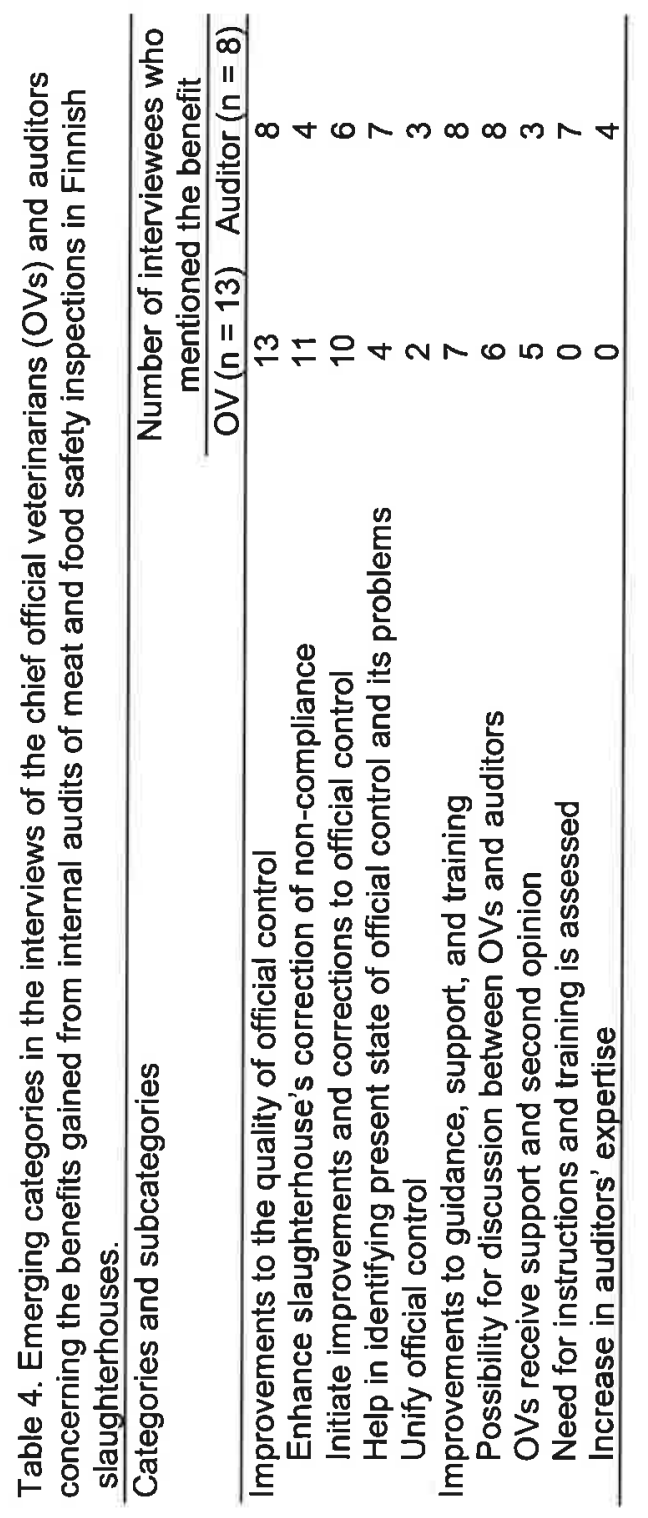




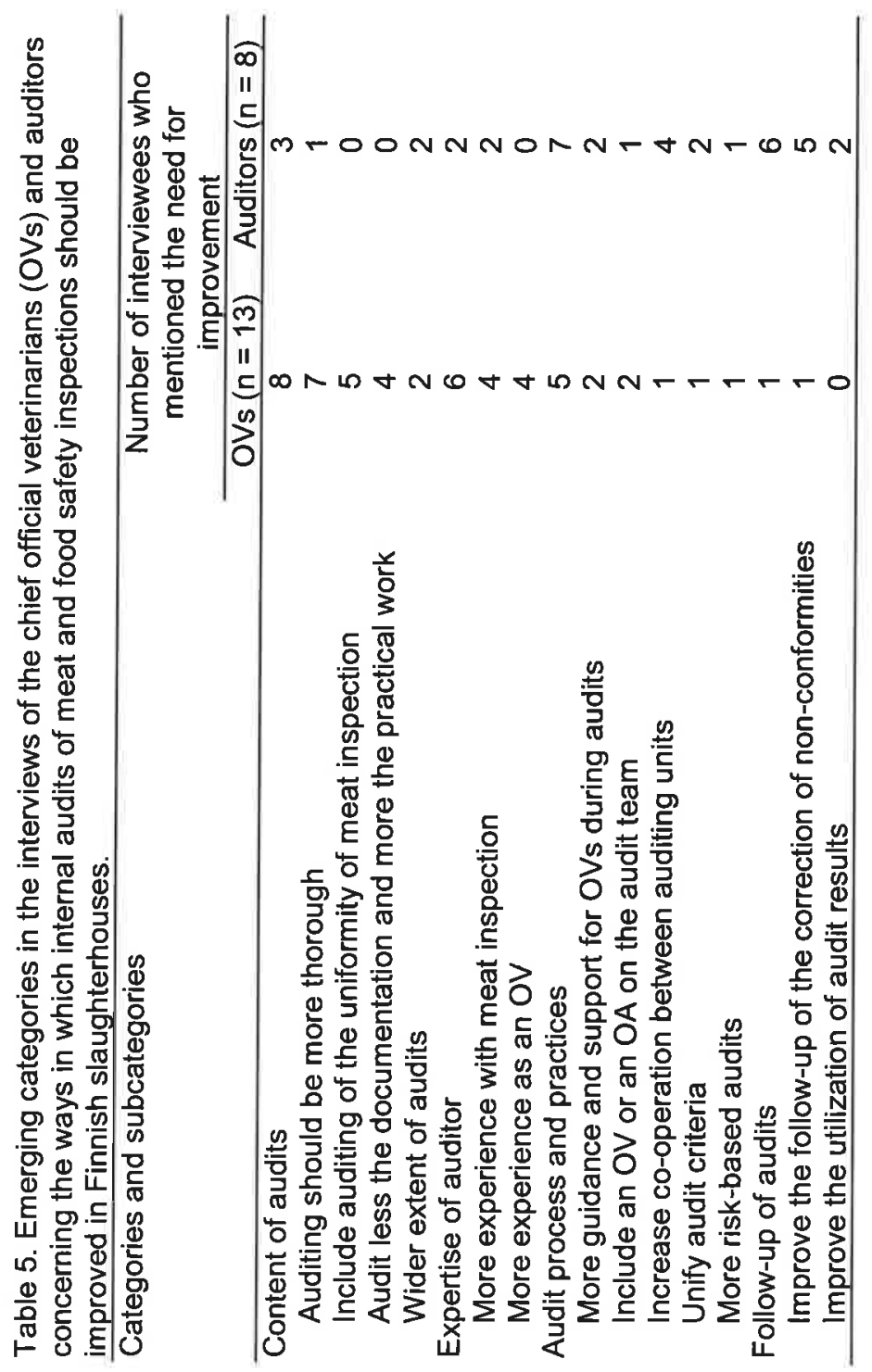


Figure captions:

Figure 1. Correction of non-conformities observed in meat inspection of swine and bovine in the internal audits of technical meat inspection in Finland in 2009-2013. OV = official veterinarian

Figure 2. Means of chief official veterinarians' $\left(O V s^{\prime}\right)(n=13)$ and auditors' $(n=8)$ answers regarding the necessity and benefits of the internal audits of official control in slaughterhouses in Finland. The number of respondents is presented in the bars and the range of answers as a black line segment. 


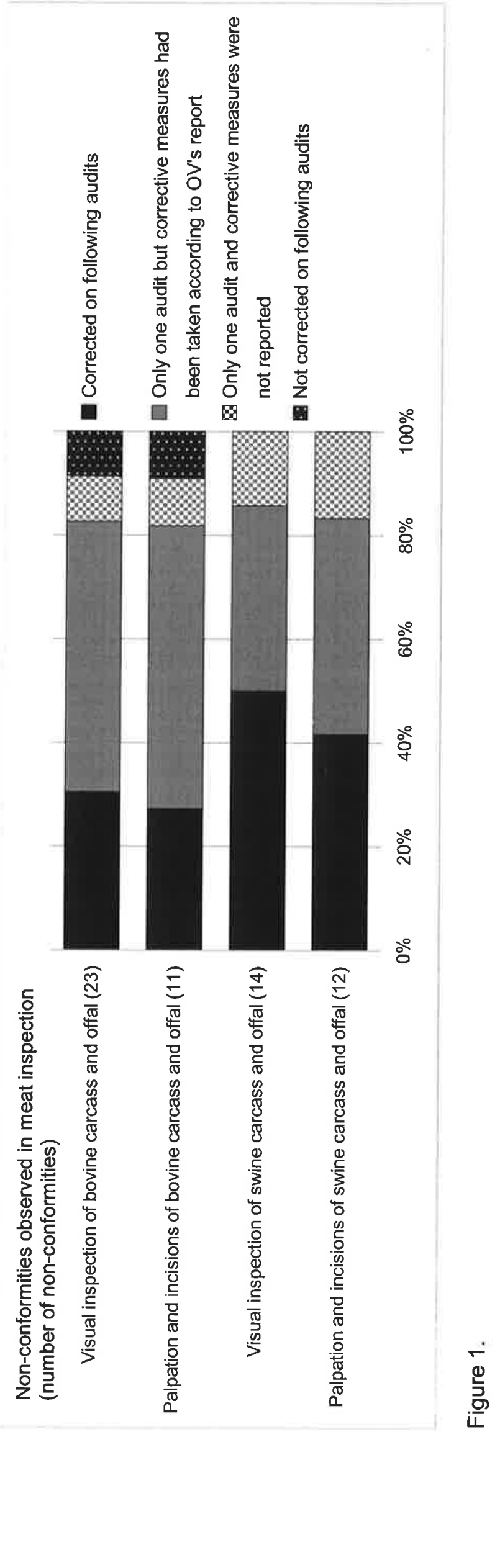




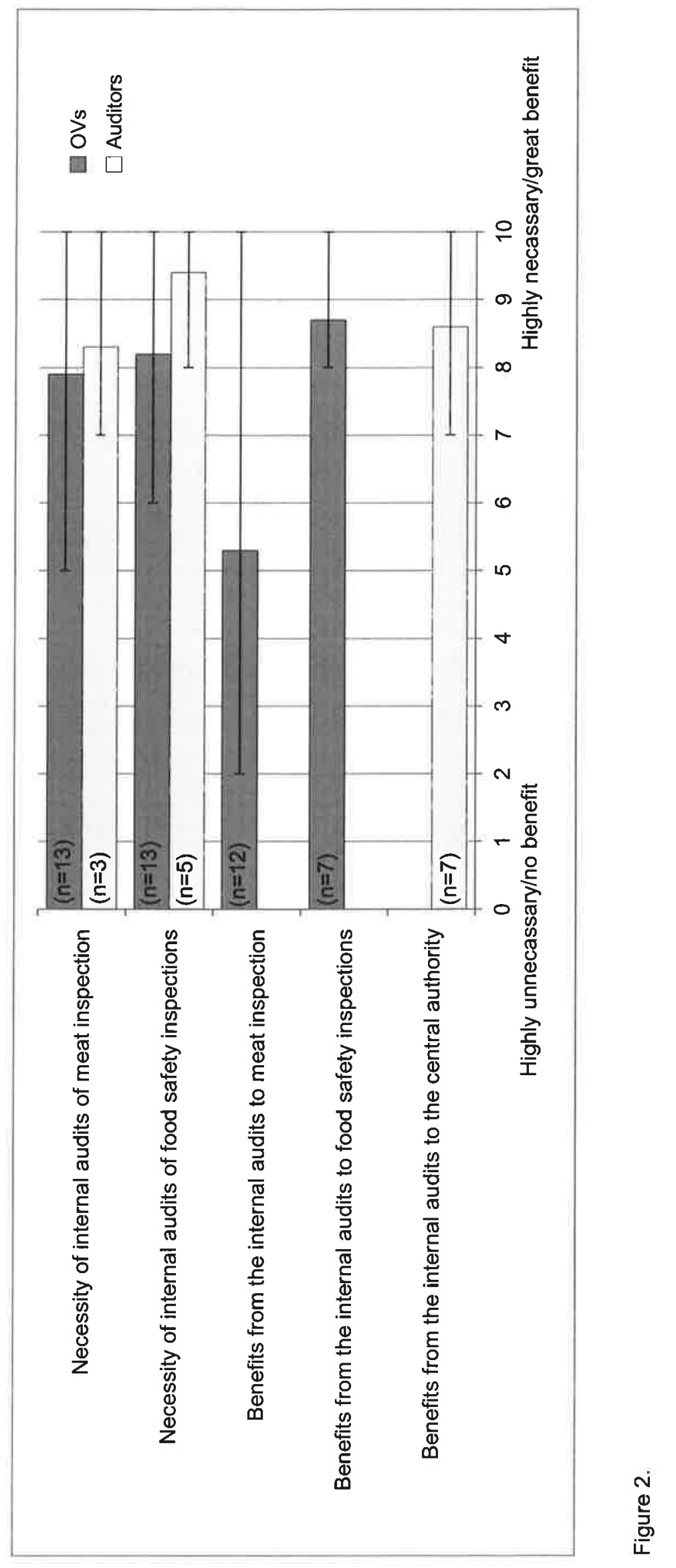

ำ 
